\title{
Erratum to: Impact of an In-visit Decision Aid on Patient Knowledge about Contralateral Prophylactic Mastectomy: A Pilot Study
}

Katharine Yao, $\mathrm{MD}^{1}$, Jeff Belkora, $\mathrm{PhD}^{2}$, Isabelle Bedrosian, $\mathrm{MD}^{3}$, Shoshana Rosenberg, $\mathrm{PhD}^{4}$, Mark Sisco, $\mathrm{MD}^{1}$, Ermilo Barrera, $\mathrm{MD}^{1}$, Alexandra Kyrillos, $\mathrm{BS}^{1}$, Jon Tilburt, $\mathrm{MD}^{\mathbf{5}}$, Chihsiung Wang, $\mathrm{PhD}^{6}$, Sarah Rabbitt, $\mathrm{RN}^{1}$, Catherine Pesce, MD ${ }^{1}$, Sandra Simovic, BS ${ }^{1}$, David J. Winchester, $\mathbf{M D}^{1}$, and Karen Sepucha, PhD $^{7}$

${ }^{1}$ Department of Surgery, NorthShore University HealthSystem, Evanston, IL; ${ }^{2}$ University of California San Francisco School of Medicine, San Francisco, CA; ${ }^{3}$ Department of Surgery, MD Anderson Cancer Center, Houston, TX; ${ }^{4}$ Dana Farber Cancer Institute, Boston, MA; ${ }^{5}$ Mayo Clinic, Rochester, MN; ${ }^{6}$ Center for Biomedical Research Informatics, NorthShore University HealthSystem, Evanston, IL; ${ }^{7}$ Massachusetts General Hospital, Health Decision Sciences Center, Boston, MA

ERRATUM TO: ANN SURG ONCOL (2017) 24:91-99 DOI 10.1245/S10434-016-5556-X

In the original article Alexandra Kyrillos's family name was misspelled. It is corrected as reflected in this erratum.

The online version of the original article can be found under doi:10. 1245/s10434-016-5556-x.

(C) Society of Surgical Oncology 2017

Published Online: 27 March 2017

K. Yao, MD

e-mail: kyao@northshore.org 